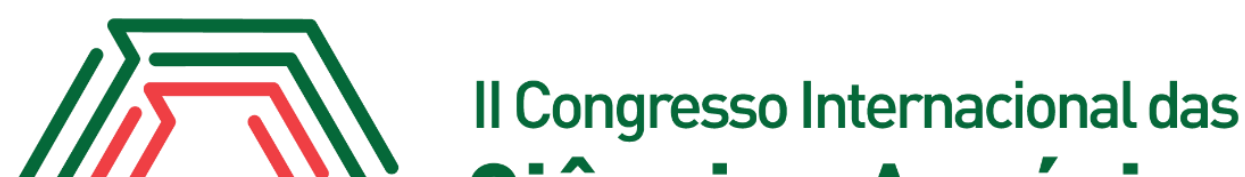 Ciências Agrárias COINTER - PDVAgro 2017
}

\section{UTILIZAÇÃO DO FÓSFORO NO DESENVOLVIMENTO DE CULTIVAR DE SOJA ADAPTADA PARA REGIÕES DE SOLOS TROPICAIS}

\author{
Apresentação: Pôster
}

\begin{abstract}
Adrielle Christina Pereira Rocha Santos ${ }^{1}$; Felipe Ferreira da Silva ${ }^{2}$; Aldean Barbosa Miranda ${ }^{3}$; Wallysson Nascimento Lima ${ }^{4}$
\end{abstract}

\section{Introdução}

A região de cerrado caracteriza-se, do ponto de vista edáfico, por possuir solos ácidos, de baixa fertilidade e baixo teor de fósforo $(\mathrm{P})$ disponível às plantas, caracterizando-se por ser um dos nutrientes mais limitantes à produção agrícola, pois a disponibilidade desse elemento, em condições naturais é muito baixa, influenciado pela fixação do elemento à óxidos de Fe e $\mathrm{Al}$ (NOVAIS etal. 2007).

O P é um elemento que tem participação fundamental em todos os metabólitos relacionados com aquisição e utilização de energia na planta. A obtenção de produtividades satisfatórias é altamente dependente da utilização de fertilizantes fosfatados,onde na natureza os fosfatos são recursos escassos e não renováveis(GRANT et al. 2001).Calcula-se que metade das reservas globais de P inorgânico estará esgotada entre 2040 e 2060 com estimativa do crescimento da população mundial em 9 bilhões (Lambers et al. 2006).

O constante crescimento da população mundial e a necessidade de práticas sustentáveis estimulam o desenvolvimento de tecnologias na área agrícola que proporcionam mais produtividade e com isso a necessidade de estudos com o objetivo de desenvolver estratégias para aumentar a

\footnotetext{
${ }^{1}$ Graduanda em Engenharia Agronômica, Universidade Estadual da Região Tocantina do Maranhão - UEMASUL, email: adriellecprs@gmail.com

${ }^{2}$ Engenheiro Agrônomo, graduado pela Universidade Estadual do Maranhão - UEMA, e-mail: fsfelipe21@gmail.com ${ }^{3}$ Graduando em Engenharia Agronômica, Universidade Estadual da Região Tocantina do Maranhão - UEMASUL ${ }^{4}$ Mestrando em Fitotecnia, Universidade Federal Rural do Semi-Árido, Mossoró-RN, email: allysson.agro@live.com
} 
eficiência das fontes de P. Uma alternativa é obter informações para nortear a tomada de decisão sobre a adoção de cultivares de sojaeficientes quanto à absorção e utilização de $\mathrm{P}$.

\section{Fundamentação Teórica}

A soja é a cultura agrícola brasileira que mais cresceu nas últimas três décadas e corresponde a 49\% da área plantada em grãos do país (MAPA, 2016). A adubação é um dos principais fatores que determinam a produtividade na cultura da soja, pois contribui para a correção da fertilidade do solo e supre as necessidades nutricionais da planta.

Em solos tropicais de cerrado a adsorção de fosfato é influenciada pelos minerais encontrados nos solos, especialmente os óxidos de Fe e Al (EBERHARDT et al. 2008). Assim, mesmo quando é praticada a fertilização fosfatada, o solodeixa de ser fonte e passa a ser dreno de $\mathrm{P}$ da solução (NOVAIS etal. 2007).

A expansão das áreas de cultivo no cerrado, esgotamento das reservas mundiais que podem provocar uma tensão geopolítica, ocrescimento populacional, a necessidade de adubação fosfatada em grandes quantidades e a preocupação com impactos ambientais, são fatores que tendem a manter elevação dos preços de fertilizantes fosfatados (PRADO 2008).Com esse cenário atual e as projeções de futuro, a busca por maiores eficiências na adubação tornaram-se estímulos à pesquisa nessa área (ELSER et al. 2011).

\section{Metodologia}

O experimento foi conduzido em condições de campo, em um Planossolo arenoso, com $\mathrm{pHCaCl}_{2}$ 4,8, CTC 2,61, SB 4,31 e P 13,5 mg.dm ${ }^{-3}$, delineamento experimental em blocos casualizados (DBC), sendo os tratamentos dispostos em esquema fatorial $2 \times 4$, com quatro repetições constituídos pela cultivar BRS 9180 IPRO, com três doses de fósforo (60, 120 e 180 kg.ha- ${ }^{1}$ ) e um tratamento controle, sem adubação fosfatada, totalizando 32 unidades experimentais (UE), cada EU com uma área de $4 \mathrm{~m}^{2}$, sementes inoculadas no momento do plantio com bactérias Bradyrhizobium japonicum e tratos culturais foram realizados para controle de plantas daninhas (capina manual) e de percevejos (inseticida CONNECT, sistêmico de princípio ativo BETACIFLUTRINA e IMIDACLOPRIDO). 
No início do estádio R1 foi realizada mensuração de altura com auxílio de uma trena, amostrando-se 10 plantas localizadas nas linhas centrais de cada parcela. A eficiência da utilização do fertilizante fosfatado foi avaliada pela seguinte equação: $E U=\frac{A L T f-A L T 0}{P f}$. Em que: EU é a eficiência da utilização do fertilizante; ALTf é a altura média das plantas que receberam fertilizante fosfatado; ALT0 é a altura média das plantas que não receberam fertilizante fosfatado; Pf é a dose do fertilizante fosfatado aplicado.

Os resultados foram submetidos à análise de variância $(\mathrm{p} \leq 0.05)$. O efeito das doses de $\mathrm{P}$ para cada cultivar foi avaliado através de regressão linear e quadrática, através do programa estatístico, Sigmaplot.

\section{Resultados e Discussões}

Ao avaliar a altura de planta da cultivar BRS 9180 IPRO, verificou-se um comportamento linear em função das doses de P. O tratamento controle, que não recebeu fertilizante fosfatado, apresentou a menor altura $93,23 \mathrm{~cm}$, acima da média descrita para a cultivar que é de $78 \mathrm{~cm}$ (VILELA et al. 2016), confirmando a expressão das características genotípicas da cultivar em condições de fertilidade semelhantes ao desse solo, com 13,5 mg.dm ${ }^{-3}$ de P, SB 4,31, CTC 2,61, V\% e m de $60,5 \%$ e $0 \%$, respectivamente de textura arenosa.

FIGURA 1. Altura média de plantas (cm) da cultivar BRS 9180 IPRO sob diferentes doses de P.

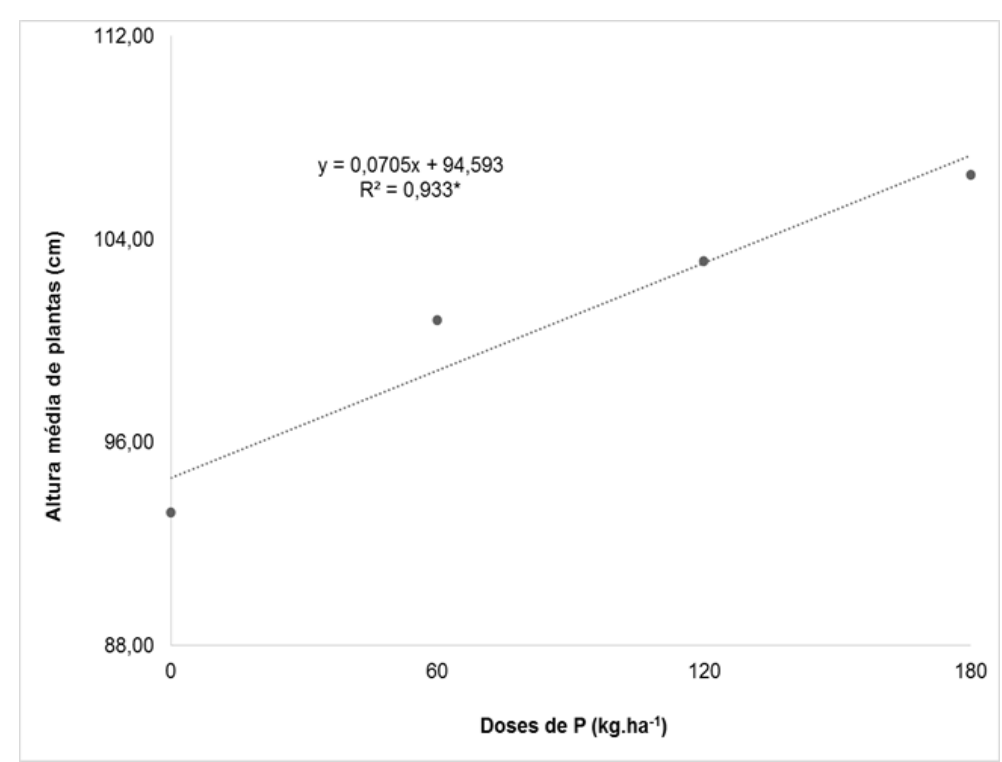

* significativo ao nível de $5 \%$ de probabilidade $(.01=<\mathrm{p}<.05)$. 
A dose elevada de fertilizante fosfatado (180 kg.ha $\left.{ }^{-1}\right)$ promoveu o maior crescimento em altura, 106,55 cm, resultados que corroboram com de Rosa et al. (2015) que, em ensaio com soja de tecnologia INTACTA avaliando as doses de 50, 100, 150 e $200 \mathrm{~kg} \cdot \mathrm{ha}^{-1}$ de $\mathrm{P}_{2} \mathrm{O}_{5}$ em Latossolo vermelho amarelo distrófico argiloso do cerrado, no Mato Grosso, verificaram que as diferentes doses de fósforo influenciaram a altura de plantas, onde os maiores valores foram obtidos com a maior dose estudada $\left(200 \mathrm{~kg} \cdot \mathrm{ha}^{-1}\right)$.

Mundstock (2005) diz que o excesso de água em anos de precipitação pluvial intensa, se reflete no excessivo crescimento vegetativo. Este fator, aliado a adequada disponibilidade de $\mathrm{P}, \mathrm{N} \mathrm{e}$ $\mathrm{K}$ podem ter contribuído para o excessivo desenvolvimento vegetativo dessa cultivar. Mauad et al. (2010) e Spader (2014) afirmam que plantas de soja com crescimento excessivo e folhas grandes, diminuem a distribuição da radiação no interior da lavoura por conta do sombreamento, diminuindo a atividade fotossintética consequentemente a formação de vagens, isso explicaria que as doses 120 e 180 kg.ha-1 de P não refletiram em retorno econômico nesse experimento.

Tabela 1. Eficiência da utilização (EU) do fertilizante fosfatado pela cultivar de soja avaliada.

\begin{tabular}{cc}
\hline Doses de P $\left(\mathbf{k g . h a}^{\mathbf{- 1}}\right)$ & BRS 9180 IPRO \\
\hline & EU \\
\hline 60 & 12,66 \\
120 & 8,26 \\
180 & 7,4 \\
\hline Os cálculos de EU foram realizados utilizando-se as médias de altura de cada dose.
\end{tabular}

A EU da cultivar BRS 9180 IPRO foi com a dose $60 \mathrm{~kg} \cdot \mathrm{ha}^{-1}$, sendo que essa cultivar alcançou 12,66 \% de eficiência de utilização do fertilizante fosfatado para esta dose (Tabela 1). Enquanto a dose de $180 \mathrm{~kg} \cdot \mathrm{ha}^{-1}$, que atingiu a maior média de altura das plantas, apresentou-se com a menor EU do P do fertilizante aplicado, 7,4 \%. A soja, por ser um dos cultivos extensivos mais importantes do Brasil, necessita que a aplicação de fertilizantes ocorra da forma mais racional possível. 


\section{Conclusões}

A cultivar testada se apresentou eficiente nas condições naturais desse solo, com um baixo teor de P,tanto no parâmetro altura, aqui apresentado, como em produção de biomassa e de vagens (dados não constam nesse trabalho). A eficiência se deu com dose $60 \mathrm{hg} \cdot \mathrm{ha}^{-1}$, atingindo 12,66 \% , no entanto, a real eficiência é a não necessidade de adubação fosfatada para a cultivar BRS 9180 IPRO em solos com essas características.

\section{Referências}

ELSER, J. BENNETT, E[M]. 2011. Phosphoruscycle: A brokenbiogeochemicalcycle. Nature. 478: 29-31. 2011.

LAMBERS, H. et al. Plantnutrient-acquisitionstrategieschangewithsoil age. Trends in Ecology\& Evolution, Amsterdam, v. 23, n.2, p. 95-103, 2008.

GRANT, C.A; FLATEN, D.N; TOMASIEWICZ, D.J; SHEPPARD S.C.A importância do fósforo no desenvolvimento inicial da planta. Instituto da Potassa e do Fosfato. Informações Agronômica, nº 95. 2001.

MAPA.SOJA - Ministérios da Agricultura, Pecuária e Abastecimento. Disponível em: <http://www.agricultura.gov.br/vegetal/culturas/soja> Acesso em 08 Abr, 2016.

MAUAD, M.; SILVA, T.L.B.; ALMEIDA NETO, A.I.; ABREU, V.G. Influência da densidade de semeadura sobre características agronômicas na cultura da soja. Agrarian, v.3, p.175- 181, 2010.

MUNDSTOCK, C. M. Soja: fatores que afetam o crescimento e o rendimento de grãos / Claudio Mário Mundstock; André Luís Thomas - Porto Alegre: Departamento de Plantas de Lavoura da Universidade Federal do Rio Grande do Sul: Evangraf, 2005.

NOVAIS, R. F.; SMYTH, T. J.; NUNES, F. N. Fósforo. Fertilidade do solo. Viçosa: Sociedade Brasileira de Ciência do Solo, 2007.

PRADO, R. M. Nutrição de plantas. São Paulo: Editora Unesp, 407 p. 2008.

ROSA, R. P. PITTELKOW, F. K.; PASQUALLI, Rodrigo.; M. Doses e métodos de aplicação de fósforo na cultura da soja. Boletim técnico safra 2014/15. Lucas do Rio Verde, MT. agosto, 2015.

SPADER, V. Características de plantas de soja associadas com alta produtividade em condição de elevada altitude. Tese (Doutorado) - Universidade Federal do Paraná. Setor de Ciências AgráriasCuritiba, 2014. 